\title{
Testing the Focal Point Theory of Legal Compliance: The Effect of Third-Party Expression in an Experimental Hawk/Dove Game
}

\author{
Richard H. McAdams and Janice Nadler*
}

\begin{abstract}
Economic theories of legal compliance emphasize legal sanctions, whereas psychological and sociological theories stress the perceived legitimacy of law. Without disputing the importance of either mechanism, we test a third way that law affects behavior, an expressive theory that claims law influences behavior by creating a focal point around which individuals coordinate. We investigated how various forms of third-party "cheap talk" influence the behavior of subjects in a Hawk/Dove or Chicken game. Despite the players' conflicting interests, we found that messages highlighting an equilibrium tend to produce that outcome. Most striking, this result emerged even when the message was selected by an overtly random, mechanical process. We obtained a similar result when the message was delivered by a third-party subject; the latter effect was significantly stronger than the former only when the subject speaker was selected by a merit-based process. These results suggest that, in certain circumstances, law generates compliance not only by sanctions and legitimacy, but also by facilitating coordination around a focal outcome.
\end{abstract}

\footnotetext{
*Address correspondence to Richard H. McAdams, University of Illinois College of Law, 504 E. Pennsylvania Ave., Champaign, IL 61820; phone: 217-333-4385; email: rmcadams@law.uiuc.edu; Janice Nadler, American Bar Foundation \& Northwestern University School of Law, 357 E. Chicago Ave., Chicago, IL 60611; phone: 312-503-3228; email: jnadler@northwestern.edu.

For their comments on an earlier draft, the authors thank Rachel Croson, Dhammika Dharmapala, Shari Diamond, Tom Ginsburg, Tom Miles, Jeff Rachlinski, Larry Ribstein, Tom Ulen, members of the research committees of the American Bar Foundation, and the participants at law faculty workshops at Connecticut, Florida State, Northwestern, and Virginia and at the law and economics workshop at Michigan. We also thank Emily Solberg for research assistance. We thank the American Bar Foundation, the Dispute Resolution Research Center of Northwestern University, Northwestern University School of Law, and the National Science Foundation for research support. This research was supported by National Science Foundation Grant SES-0351530.
} 


\section{INTRODUCTION}

Law-and-economics theorists commonly view law as a tool for facilitating cooperation. Legal sanctions change incentives so that individuals will not defect from Pareto-optimal arrangements. Another important but neglected effect of law is to facilitate coordination. Because of the publicity commonly given to and expected for law, legal pronouncements can create common knowledge about governmental expectations. Even aside from the sanctions government uses to enforce its expectations, in a coordination situation, a legal pronouncement can make the prescribed outcome salient or "focal," thereby creating self-fulfilling expectations that this outcome will occur. Broadcasting the rule "drive on the right," for example, is likely to prompt some compliance independent of the threat of legal sanctions, merely because the common knowledge that everyone heard this particular message makes the named behavior focal.

It is exceedingly easy to overlook this coordinating power of law. One reason is that two other explanations have long dominated theory and empiricism on the subject of legal compliance. Most economic analysis assumes that sanctions are the sole mechanism by which law achieves compliance (via deterrence or incapacitation), while most psychological and sociological theories emphasize the perceived legitimacy of law as the primary explanation for compliance (via social and institutional reinforcement of moral norms). The debate between these camps obscures the possibility of any alternative. In addition, the common joinder of law with sanctions and legitimacy makes it extraordinarily difficult to discern whether law has a power independent of these forces. Finally, even if one is prepared to look beyond the two prevailing theories, the problem of coordinating among multiple equilibria stands a bit outside the mainstream of game theory that is applied to law. Indeed, many law-and-economics scholars think of coordination as relevant to only a narrow domain of social life that does not include the conflict that law seeks to resolve.

Despite this resistance, a few theorists have offered coordination as another mechanism for generating legal compliance, a third reason why people obey law (Cooter 1998; Garrett \& Weingast 1993; Hardin 1989; Hay \& Shleifer 1998:400-01; McAdams 2000a; Posner 2000:177-79). These coordination explanations employ rational choice tools and, like other economic theories, avoid complex notions of legitimacy. Despite these differences from psychological and sociological approaches, however, coordination theories 
similarly conclude that law can generate some compliance expressively, apart from its sanctions. Without denying the power of sanctions or legitimacy, the coordination explanation claims that law influences behavior independently of either. (There are also rational choice explanations of the expressive power of law that do not rely on coordination. See, e.g., Dharmapala \& McAdams 2003; McAdams 2000b; Kahan 2000.)

There has, however, been little empirical testing of these novel theories. Though several experiments document the power of recommendations in "conflict-free" coordination games (where subjects agree on what equilibrium is best), law commonly addresses coordination situations with genuine conflict (where subjects rank the equilibria differently). There has been almost no testing of the claim that mere "cheap talk" from third parties can influence behavior in such games. To remedy this gap, we conducted an experiment to examine whether and how cheap-talk messages influence play in a Hawk/Dove game. Here, we present our findings, which support the claim that third-party expression can by itself influence behavior in coordination situations that model legal disputes. We emphasize two points about the relationship of the current study to the larger topic of legal compliance. First, by testing an expressive theory, we do not imply a rejection of compliance theories that emphasize sanctions or legitimacy. Second, by testing a coordination theory, we do not imply a rejection of other expressive theories. Indeed, we identify below the limited domain in which coordination theories apply.

This article proceeds as follows. Section II sets forth the coordination or focal point explanation of law's expressive power. Section III reviews the relevant empirical literature on the subject. Section IV describes our experiment. Section V concludes.

\section{Coordination Theories of Expressive LAw}

There is a recent turn in applied game theory toward the importance of coordination. This new work focuses not on the simple but rare pure coordination game (such as the choice of driving on the left or right side of the road), but on "mixed-motive" games (Schelling 1960) that combine an element of conflict with a common interest in coordination. We provide examples below. For a theory of legal expression, the key is that these games have multiple equilibria-two or more outcomes that satisfy the Nash crite- 
rion that no player would benefit by unilaterally switching strategies. With multiple equilibria, the outcome that emerges depends, by definition, on features other than the payoffs. In this setting, law might be able to influence behavior for reasons other than its ability to change payoffs, via sanctions. This section provides the necessary background on coordination and focal points, and then explains the expressive theory our experiment will test.

\section{A. Background on Coordination Games and Focal Points}

Coordination theories of expressive law apply only in situations of multiple equilibria. (We emphasize that the focal point theory does not predict an expressive effect outside of this situation.) Most law-and-economics analysis considers the problem of multiple equilibria only as it arises in iterated versions of the $n$-person prisoners' dilemma. But the need to coordinate among multiple equilibria is more general. A common illustration of a pure coordination game is the choice between driving on the left or right side of the road. There are two pure strategy equilibria with identical payoffs-where everyone drives on the left and where everyone drives on the right. But the fact that all individuals share some interest in avoiding the noncoordinated outcome-where some drive left and others on the right-does not guarantee coordination.

By definition, when more than one equilibrium is possible, a player's choice of strategy is not fully determined by the payoffs. In these situations, Schelling (1960) observed that any feature of a coordination equilibrium that draws attention to itself, making it "stand out" among the equilibria, will tend to produce self-fulfilling expectations that this salient equilibrium will result. Players tend to select an equilibrium that is "unique" in some nonpayoff dimension merely because that uniqueness, when sufficiently plain, causes each player to expect every player to focus on it. For example, Schelling asked New Haven residents to name the place and time they would meet someone in New York City on a given day, if they had failed to communicate more specifically on the subject. Though there is an extremely large number of possibilities, over half the individuals named the same place-Grand Central Station-and almost everyone named the same time-noon. Later experiments confirm that where nothing in the mathematical structure of the game favors any single outcome, a nonpayoff feature that makes one equilibrium psychologically "focal" tends to cause individuals to choose the strategy that produces that equilibrium (see Mehta et al. 1994). 
Recent years have witnessed a new interest in coordination and focal points. A number of scholars in economics and political science use the theory to explain the contingency or path dependence of culture. Kreps (1990) first used coordination to explain the divergent "corporate culture" of firms. For a review of the subsequent literature, see Hermalin (2001). More broadly, Chwe (2001) explains the form social rituals take by their ability to generate the "common knowledge" needed to solve a coordination game. Greif (1994) explains how different "cultural beliefs"-individualist and collectivist-led two premodern societies-the Genoese and Maghribis-to develop different trading practices and institutions for solving an iterated principal-agent problem with multiple equilibria (see also Bednar \& Page 2003; Chong 2000).

The theory we explore in this article is consistent with this line of coordination research, but has a different focus. The above papers emphasize how past solutions "naturally" serve as focal points for new coordination problems. When a new coordination situation arises in a society, the nonpayoff features that are likely to determine what equilibrium emerges are patterns of thought (schema, frames, etc.) unconsciously borrowed from other coordination situations in that society. We instead emphasize the possibility of intentional, ongoing "construction" of focal points-that individuals anticipating the possibility of coordination problems design a process for ensuring that some solution is focal (see Garrett \& Weingast 1993).

One possibility is dialogue. In pure coordination games, the simplest way to create a focal point is by communication and agreement. Many experiments demonstrate that the players can increase their level of coordination in such games by engaging in "cheap talk": costless, nonbinding, and nonverifiable communication (Crawford 1998 provides a review).

Schelling (1960), however, was interested in cases where the individuals could not communicate and/or could not agree. In such cases, he claimed, a third party could create a focal point merely by suggesting a possible solution. His example of third-party influence in a pure coordination game was a prominent sign posted throughout a department store suggesting where lost parties should reunite. Even though the parties have not agreed in advance to follow the sign's suggestion, we can imagine that, once lost, they would gladly obey it.

For law, however, the crucial question is whether third-party suggestions can influence behavior outside of pure coordination games. Games of pure coordination (such as the choice between driving on the left or right or where to meet when lost) are rare. Their rarity probably explains why the- 
orists slight the value of coordination to law. But an element of coordination is present in common situations that Schelling called "mixed-motive" games. In games such as Battle of the Sexes and Hawk/Dove (discussed below), each player prefers at least two equilibrium outcomes to at least one nonequilibrium outcome, but the players rank the preferred equilibria differently. Thus, there is a shared interest in coordinating to avoid a nonequilibrium outcome. However, there is also conflict because one individual's favored equilibrium is another individual's disfavored equilibrium.

With mixed-motive games, it is less certain that communication between players will facilitate coordination (because each individual may use cheap talk merely to insist on his or her own preferred outcome). Schelling claimed, however, that third-party cheap talk could still provide a solution to such games. He offers this example: imagine the effect of a bystander who steps into an intersection to direct traffic when the traffic light is broken. Drivers approaching an intersection on different roads each want to coordinate to avoid a collision, but each prefers to proceed immediately through the intersection while the other waits. Schelling posits that drivers will tend to obey the hand signals of the bystander, that is, that this third party's expression will influence behavior even though, as cheap talk, it does not change the payoffs of the individuals in the game.

\section{B. The Focal Point Theory of Expressive Law}

A number of theorists have identified the possibility that law works in part by constructing a focal point for the solution of coordination games. Russell Hardin (1989) first identified the constitution as a solution to a problem of coordination (and not a social contract solution to a prisoners' dilemma). Though he did not emphasize the focal point nature of the constitutional solution, others have (Hay \& Shleifer 1998:400-01; Strauss 1996:910-19). Garrett and Weingast (1993) present a more complete theory, claiming that international adjudication works expressively by constructing a focal point solution to ambiguities that inevitably arise in international treaties (see also Cooter 1998; Posner 2000:177-79). McAdams (2000a) seeks to generalize and extend these claims into a focal point theory of expressive law. McAdams claims that third-party cheap talk works not only in pure coordination games, but in all mixed-motive coordination situations. Here, law works the same way as does Schelling's bystander in the intersection directing traffic. By 
making one outcome salient, legal rules and judgments can guide expectations toward that outcome and influence behavior independent of sanctions (see also Ginsburg \& McAdams 2004; McAdams forthcoming).

The focal point theory relies on three empirical claims.

1. The first is that the need for coordination is pervasive because mixed-motive games plausibly model common social conflict.

2. The second claim is that law, by publicly endorsing a particular equilibrium, tends to call the players' attention to that outcome.

3. The third claim is that, in such games, any third-party expression that calls the players' attention to a particular equilibrium tends to produce that equilibrium.

As we explain below, our experiment tests the third of these claims-that salient third-party expression influences behavior in these games. In the next sections, we explain further the first and second claims, so as to establish the practical relevance of proving the third.

\section{Claim 1: The Need for Coordination is Pervasive}

Much of the social conflict that law addresses can be modeled as a mixedmotive game involving an element of coordination. As an abstract matter, it is very common for games of any complexity to have multiple equilibria and with multiple equilibria it is common that the players mutually prefer to avoid at least one of the possible outcomes. If so, then the element of coordination (as we use the term) is pervasive. We will, however, illustrate the general point with two specific mixed-motive games, each of which represents common situations the law addresses. We first introduce each game, and then explain how it models real-world conflict.

The first example is the Battle of the Sexes (BOS) Game (see Figure 1). Here, two players choose between Strategies 1 and 2, where there is some mutual advantage from "matching" the other player's strategy. As a result, the two pure strategy equilibria are S1/S1 and S2/S2. But unlike a pure coordination game, the payoffs at these points are unequal. Player 1 prefers $\mathrm{S} 1 / \mathrm{S} 1$ (with a payoff of 3 ) to S2/S2 (payoff of 2), while Player 2 has the opposite preferences. Despite this conflict, the players have a common interest in coordinating to avoid the nonequilibrium outcomes, where each receives 0 . 
Figure 1: A Battle of the Sexes game.

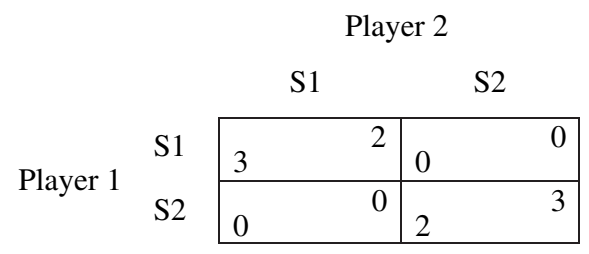

The structure of BOS illustrates common situations the law seeks to address. As one example, suppose two siblings jointly inherit two family heirlooms and that the costs of sharing them are prohibitive. A conflict arises because each prefers one of the heirlooms (that each values at 3) to the other (that each values at 2). But they retain an interest in coordinating because if they fail to agree on an allocation, the items will both be sold and the proceeds divided, which will cause them to lose significant sentimental value. (One may object to using the payoff of 0 for this outcome, but the structure of the game remains the same if we replaced the 0 s in Figure 1 with a payoff of 1 . What is important is that each player regards these nonequilibrium outcomes as the worst possible outcome.) Another example is standard setting. In many markets, participants gain by standardizing certain dimensions of interconnecting components (e.g., regarding high definition television) or certain aspects of transactional form (e.g., a formula for reporting an annual interest rate). Two participants may conflict over what standard emerges-S1 or S2-because of the different distributional consequences of each, but they may retain a mutual interest in coordinating on some standard instead of none (see, e.g., Ahdieh 2004; Brown \& Ayres 1994). Thus, the heirloom example represents the kind of conflict legal adjudication might address; the standard setting is a conflict that regulation might address.

The second example is the Hawk/Dove or Chicken game (see Figure 2). Here, each player chooses between an aggressive strategy-"Hawk"where one insists on getting one's way and a passive strategy- "Dove"where one defers to others. In a two-person version, the game is Hawk/Dove when both players rank the four possible outcomes as follows, starting with the best: (1) playing Hawk against Dove; (2) playing Dove against Dove; (3) playing Dove against Hawk; and (4) playing Hawk against Hawk. The pure strategy equilibria are Hawk/Dove and Dove/Hawk. 
Figure 2: A Hawk/Dove or Chicken game.

Player 2

\begin{tabular}{cc|cc|cr|}
\multicolumn{1}{c}{} & \multicolumn{2}{c}{ Dove } & \multicolumn{2}{c}{ Hawk } \\
\cline { 3 - 6 } Player 1 & Dove & 1 & 1 & 0 & 2 \\
\cline { 3 - 6 } & Hawk & & 0 & -1 & -1 \\
\cline { 3 - 6 } & & & & &
\end{tabular}

The structure of Hawk/Dove (HD) models disputes in at least two ways. First, one can think of the Hawk/Hawk outcome as a form of fighting: a literal brawl, an embarrassing shouting match, or some other "clash" that both players regard as the worst possible outcome. In Schelling's example of two drivers approaching an intersection on different roads, "Hawk" is the strategy of driving on, "Dove" is the strategy of stopping, and the Hawk/Hawk outcome is a collision. As another example, suppose two individuals are sitting near each other in a public place when one pulls out a cigarette and the other requests that the first not smoke it. At this point, Hawk is the strategy of insisting on getting one's way, Dove is the strategy of giving in to the other's preference, and the Hawk/Hawk outcome might be a shouting match. Or, if two neighbors disagree about the precise location of their shared property boundary, Hawk is the strategy of treating the disputed land as one's own, Dove is the strategy of deferring to the other's claim, and the Hawk/Hawk outcome might be violence.

In all these cases, one may wonder what the Dove/Dove outcome represents. One possibility is that it means the game starts over. If two cars approaching an intersection both stop, they must then decide which will go first, which is also a Hawk/Dove game. The same may be true in the property and smoking cases if one imagines that Dove/Dove plausibly permits either player to switch to Hawk in the next time period, where such switching would be implausible once one of the equilibria (where one plays Hawk and the other Dove) is reached. Technically, these possibilities are no longer Hawk/Dove games, but they still illustrate the point that mixed games involving coordination model common situations. In any event, we could also imagine Dove/Dove as seeking to split the difference (dividing the disputed land or smoking half a cigarette) or as flipping a coin to see who gets their way. 
All these examples represent the kinds of conflict law addresses by regulation or adjudication. The most generally applicable example is where Hawk/Hawk results in violence. In this case, although the outcome of Hawk/Hawk for each player is uncertain-one might win or lose the "fight"-the expected value is the worst possible outcome for both players because the cost of fighting is high relative to the value of the disputed resource. This general condition is an important limitation: when one or more players value the object in dispute highly enough relative to the costs of "fighting" (because a player values the object so highly or expects to incur so few costs from fighting), then the game has only one equilibrium and no element of coordination. Yet in many cases of real-world conflict, the matter in dispute is literally not worth fighting over, so the situation is appropriately modeled by the HD game.

HD also models disputes in an entirely different way, where Hawk/Hawk represents the failure of either party to supply a public good. Theorists commonly model public goods as a prisoners' dilemma, where the efficient outcome is universal contribution but where each is better off not contributing no matter what the other does. But in some situations, the efficient outcome is for only one player to provide the good and there are multiple equilibria in which just one of the multiple players does provide the good. In this situation, each prefers the other to bear the cost of providing the public good, but each would rather provide it than suffer its absence. Thus, Hawk is the strategy of not supplying the good, Dove is supplying it, and Hawk/Hawk means everyone loses the benefit of the good. In this setting, the Dove/Dove outcome occurs when both parties supply the good, which, by hypothesis, is inefficient.

One example is the supply of care for children and individuals requiring rescue. In some situations, one rescuer or caregiver is more efficient than having two individuals try to share the burden. Everyone may consider it the worst outcome for the child to be neglected or for the person needing rescue to die or suffer severe injury. Yet each might still be sufficiently selfish to prefer that someone else provide the care. Thus, there is a conflict over who will provide care but a common interest in coordinating to ensure that care is given. The law addresses issues like these by regulating and adjudicating duties of care (cf. Harel \& Jacob 2002).

BOS and HD are two of the simplest mixed-motive games, but more complex games capture nuances omitted from the above examples. For example, a single dispute may involve a number of stages of escalating conflict leading up to a final BOS or HD game. Or a dispute may involve an 
indefinite number of rounds, each of which is costly for each player, with the winner being the one willing to stay in the game the longest. (Regarding this "war of attrition" game, see Fudenburg \& Tirole 1991; Sugden 1986.) Or certain disputes may recur among players who recognize each other, so that they seek in each round to establish a reputation for playing aggressively in future rounds. The key point is that a great many of these games have multiple equilibria where the players mutually prefer to avoid outcomes of the most costly conflict. Because the players' strategy choice then depends on expectations not entirely determined by the payoffs, there is room for expressive influence.

\section{Claim 2: Law Frequently Produces Salience}

Law frequently creates widespread publicity for a particular outcome. Before disputes arise, prospective legal rules can make salient a particular manner of interaction, as rules against smoking in certain situations make salient the outcome where smokers play Dove and nonsmokers play Hawk (see McAdams 2000a). After disputes arise, a legal adjudicator may make salient the particular resolution expressed in a particular judgment, as where the neighbor who "wins" a lawsuit plays Hawk against the neighbor who lost (see McAdams forthcoming). In both kinds of cases, law does not always make a required behavior salient, but it often does.

We think the claim sufficiently plausible to merit little comment, except to note the parallel to Chwe's (2001) analysis of ritual. Chwe explains the form that social rituals take by their ability to generate the common knowledge needed to solve a coordination game. The simplest way to create common knowledge among a population is a ritual attended by the entire population. But Chwe (2001) also identifies mechanisms to create common knowledge among a physically dispersed population. (See Chwe 2001:23 (a new regime's units of weights and measures), 2001:37-60 (advertising), 2001:91-92 (morning newspaper).) He gives some examples of rituals that publicize the power and authority of the state, but Chwe omits what we think is one of the more interesting examples of his theory: the ritual of law. Among the many public messages that compete for individuals' attention, law is typically among the most salient. The processes of creating law and adjudicating legal disputes are public and publicized rituals that can generate common knowledge (of the government's expectation of certain conduct), making salient the outcome the law prescribes.

Other types of expression can produce the same effects. Indeed, law competes with nonlegal expression with varying results. McAdams (2000a) 
notes three reasons law is often more influential than competing expression: law is frequently more publicized; the perceived legitimacy of law can make its message "stand out" among other messages; and, because of the first two effects, legal actors may enjoy a reputation for solving coordination problems by having accurately forecasted in past cases which equilibrium would emerge. In any event, even if law has no comparative advantage in constructing focal points, a positive theory of legal compliance should include this effect.

We assume, therefore, that the law frequently addresses mixed situations of coordination and conflict, and that law frequently makes one equilibrium in such games salient. Now we turn to the third and final empirical claim: that in these situations, third-party cheap talk (including law) can influence behavior merely by making one outcome salient.

\section{The Effect of Expression on Coordination: EXISTING LITERATURE}

When Schelling (1960) introduced the idea of focal points, he emphasized that this aspect of game theory was inherently empirical, dependent as it is on the shared knowledge and cultural understandings of those in the game. As noted above, plenty of research demonstrates that cheap talk between the players in a coordination game will influence the players' behavior (see Crawford 1998; Valley et al. 2002). More to the point, some experiments also establish that third-party expression can influence behavior in certain coordination situations (see Bohnet \& Cooter 2001; Brandts \& Holt 1992; Brandts \& MacLeod 1995; Chaudhuri \& Graziano 2003; Croson \& Marks 2001; Schotter \& Sopher 2003; Tyran \& Feld 2002; Van Huyck et al. 1992; Wilson \& Rhodes 1997). As discussed below, these experiments are an important beginning. They illustrate the potential for establishing experimentally the focal point theory. Yet, for two reasons the existing literature is not entirely adequate to assess whether or how third-party expression influences behavior in the type of situations that law addresses.

The first limitation is the nature of the games employed in existing experiments. As noted above, law frequently addresses conflict between individuals. Compliance with law often involves getting one party to a dispute to "give in" to the other. The HD game is useful for modeling this situation. However, there are no existing experiments testing third-party expression in conflict-intensive HD games. Rather than games mixing conflict and coor- 
dination, most experiments examining the effect of third-party expression employ either pure coordination games (Van Huyck et al. 1992; Wilson \& Rhodes 1997) (game "A") or games where the individuals agree on which equilibrium is best (Bohnet \& Cooter 2001; Chaudhuri \& Graziano 2003; Van Huyck et al. 1992) (game "B”). Where other mixed games are used, they are too complex to model legal disputes, arising in experiments intended to test abstract theories of equilibrium refinement (Brandts \& Holt 1992; Brandts \& McLeod 1995) or "sunspot equilibria" (Duffy \& Fisher forthcoming). The one exception is the intergenerational Battle of the Sexes game in Schotter and Sopher (2003), which we discuss below.

The second limitation in existing research is the manner in which the experiments model expression. We think it desirable to break down expression into various components, beginning with the most minimal, and then to determine the contribution each component makes. In particular, the most basic thing expression can do is simply to call attention to a particular outcome; so it would be desirable to know whether this "ostensive" feature exhausts the effect of expression, or whether other features (discussed below) make an important contribution. Yet all existing experiments treat third-party "expression" as an undifferentiated whole. ${ }^{1}$

A few studies merit further discussion. Two explicitly study the expressive effect of law. Bohnet and Cooter (2001) had subjects play a multiperson game similar to "stag hunt" or "assurance," where subjects each choose between strategy "L" and "R." In the control condition, many groups failed to achieve the Pareto-optimal equilibrium, in which everyone plays R. In the expressive condition, the payoff for the Pareto-inferior strategy (L) was raised by 20 cents, but this change was offset by a 10 percent probability that anyone playing this strategy would be "punished" by 200 cents. Bohnet and Cooter found significantly greater play of the Pareto-optimal strategy in this "penalty" condition, even though the expected pay-off values of the two strategies are exactly the same as the corresponding strategies in the control condition.

Tyran and Feld (2002) had groups of three subjects play a public goods game. Subjects decided whether to contribute to a public good, where with-

\footnotetext{
${ }^{1}$ Moreover, in most research, the experimenter merely reads the suggestion to the subjects, increasing the possibility of demand characteristics, where subjects comply in an effort to please the experimenter. In the experiment reported here, we instead attempt to carefully involve the subjects in the delivery of messages, following Wilson and Rhodes (1997), Schotter and Sopher (2003), and Tyran and Feld (2002).
} 
holding (not contributing) always generated a higher material payoff for an individual than contributing (no matter what other subjects did). In some conditions, subjects voted on a "deduction" rule, knowing that, if a majority voted for the rule, the payoffs for withholding would decline by a certain amount. In one such condition- "mild law"- the deduction was sufficiently small that an individual would still always be materially better off withholding than contributing. Contrary to economic prediction, there was some contribution in all conditions. But in the mild law condition, individual contributions were three times higher than either the control condition (with no deduction) or a condition where the same deduction rule was imposed exogenously, without a vote.

Both experiments demonstrate the potential for experimentally testing the effect of legal expression on behavior. They reveal the power of expression in games of multiple equilibria, but neither study uses the HD or similar game and neither disaggregates the components of expression. First, Bohnet and Cooter (2001) explicitly test expression in a setting like an assurance game, where all players prefer the same equilibrium. Tyran and Feld (2002) offer what seems to be a very strenuous test by using a public goods game where the material payoffs should compel a single behavior contrary to the expression. However, we follow Farrell and Rubin (1996:113 n.14) in believing that nonmaterial payoffs can change the nature of such games. Considerable evidence suggests that, when material payoffs appear to create a single equilibrium (such as zero contribution), some individuals cooperate because they directly gain utility from reciprocating the other subjects' strategy and/or producing a "fair" outcome (Fehr et al. 2002; Henrich et al. 2001; McCabe et al. 1998). If so, then the total payoffs may create an assurance game; these individuals want to contribute if others contribute, but to withhold if others withhold. It is difficult otherwise to explain the contributions Tyran and Feld observed. But once we say the efficient outcome in their game is an equilibrium, then we again have a game where the expression encourages an equilibrium everyone most prefers.

Consider more precisely why a HD game offers a more strenuous test of the expressive effect. In experiments like Bohnet and Cooter (2001) (and Tyran \& Feld 2002 as we reinterpret it), because the expression encourages the equilibrium that is the best outcome for all players, each player prefers that everyone complies with the message even after it is received. To emphasize this point, suppose that each player has a "magic pill" that he or she can use to make all the players forget what the message was. When the message 
encourages everyone's preferred outcome, no one would use the pill. By contrast, in the HD game, it is only ex ante-before receiving the messagethat all players are better off if everyone follows whatever message they receive. Ex post-after the third party speaks-the situation changes. As in a dispute, the expression will identify one player as the "loser," who is told to play Dove against Hawk, and is worse off if everyone complies. If the loser had a magic pill, he or she would use it.

To illustrate given the Figure 2 payoffs, the mixed strategy equilibrium is for each player to choose Hawk or Dove with equal probability. At this equilibrium, the expected payoff for either strategy is 0.5 . (At the mixed equilibrium, playing Dove produces a 50 percent chance of receiving 1 and a 50 percent chance of receiving 0 , for a net expectation of 0.5; playing Hawk produces a 50 percent chance of 2 and a 50 percent chance of -1 , for a net of 0.5.) If the players instead correlate their strategies with a legal pronouncement endorsing one outcome, and assuming each has a 50 percent chance of securing his or her preferred announcement, then the expected payoffs rise to 1 . (When everyone follows a message based on a coin flip, each player has a 50 percent chance of earning 2 (playing Hawk against Dove) and a 50 percent chance of earning 0 (playing Dove against Hawk), producing an expectation of 1.) Despite the ex ante improvement, once the expression occurs, the "losing" player expects a payoff of 0 if both players follow the expression, which is worse than the mixed-strategy payoff. At this point, the loser wants to resist the message. This sharp ex post conflict in a HD game makes it a better model of legal disputes and a more strenuous test of the claim that mere expression can influence behavior.

The second point about these two experiments (that explicitly aim to study expressive law) is that they treat legal expression as an undifferentiated whole. Bohnet and Cooter (2001) model legal expression by stating in the experimental instructions that choosing one of the strategies (L) "will be punished" with a given probability of 10 percent, but exactly offsetting the expected punishment by a general increase in the payoffs for that strategy. Unfortunately, this approach potentially confounds at least two ways in which law may influence expectations: the nonnormative effect of simply "pointing to" a particular outcome and the normative effect of condemning an outcome by labeling part of its payoff a "punishment." Also, embedding normative language in the experiment instructions creates the risk that the behavioral effect derives from the subjects' desire to please the researchers (demand characteristics) rather than the ability of legal expression to influ- 
ence behavior. ${ }^{2}$ Tyran and Feld (2002) ingeniously use voting in their experimental design, which certainly minimizes demand characteristics. However, voting itself consists of multiple components, including communication and legitimacy, each of which may independently contribute to creating a focal point. Moreover, voting for a rule may not be the appropriate model of law in a representative democracy, where citizens usually vote for a leader who then votes for a rule, rather than voting for the rule itself.

Finally, Schotter and Sopher (2003) do not seek to study the influence of legal expression, but they demonstrate the effects of third-party cheap talk in an "intergenerational" Battle of the Sexes (BOS) game. Each subject in their experiment played the game for one of its many rounds. Players in generation (round) $t$ could offer private, open-ended advice (via a computer screen) to their own "successors" in generation (round) $t+1$, where each player received additional payoffs based on how well his or her successor did. Schotter and Sopher find that this advice strongly influenced the players who received it, despite the fact that the information set of the "parent" is "virtually" the same as that of the "child," and despite the fact that the private advice is not common knowledge.

Though the intergenerational version of the BOS game does not intuitively model legal disputes (as it was not intended to), Schotter and Sopher's study importantly demonstrates that cheap talk can influence behavior even in games with some conflict. But even though the players in BOS disagree on the best outcome, the degree of conflict in the BOS game is qualitatively less than that in the HD game. Recall from above that the players in a BOS game will gain ex ante if all follow a message that will give each a 50 percent chance of obtaining their favored outcome. But unlike the HD game, this advantage also exists ex post. In a BOS game, after the coordinating expression occurs, the "loser" will gain more from having both players comply with the expression than he or she would gain by returning to the mixed-strategy equilibrium. The reason is that the two equilibria in the BOS game represent a player's first and second best outcomes, so that coordinating expression gives the "losing" player his or her second-best outcome. This compares favorably to the mixed-strategy equilibrium, which includes, in addition to

\footnotetext{
${ }^{2}$ There is the possibility that Bohnet and Cooter failed to make the penalty "nondeterring" as they suppose. If the subjects were risk averse, they would regard the uncertainty associated with the penalty - a 10 percent chance at a 200 -cent fine-as worse than the expected loss of 20 cents. Risk aversion might then cause the greater compliance with the penalty.
} 
the possibility of one's best outcome, some probability of reaching the two nonequilibrium outcomes. Each of these is the player's worst outcome. By contrast, the loser in the HD game receives only his or her third-best outcome (Dove against Hawk), which is worse than the mixed-strategy equilibrium. Thus, the Schotter and Sopher experiment does not test expression in a context where the losing player has an incentive to resist the expression.

Moreover, like other experiments, Schotter and Sopher do not disaggregate the components of expression. Their advice combines several features at once: it "points to" a strategy, it represents an intentional choice by the advice giver, and that advice giver presumably enjoys significant legitimacy because his or her payoff structure is based on how well the subject does. In addition, Schotter and Sopher did not standardize the expression being used, but allowed subjects to send open-ended messages that could include reasons for the advice given, which may introduce different expressive features across advice. Thus, we are left to wonder which features of the expression were strictly necessary to the result.

In sum, existing experiments do not test expression in the contexts that best model legal disputes, and do not carefully isolate the possibly distinct components of legal expression. Given these limitations, there is much to be learned by further study.

\section{THE EXPERIMENT}

In field studies, it is extremely difficult to isolate possible causes of compliance apart from sanctions and legitimacy, much less to identify the particular components of legal expression that may influence behavior. Experiments therefore provide a useful starting point for systematically examining the influence of legal expression on behavior in coordination situations.

\section{A. Method}

1. Design

The two crucial parameters for testing the effect of expression are the strategic context and the nature of the expression. As to context, we used a Hawk/Dove game for the reasons explained above. We had the subjects play a series of one-shot HD games based on the payoffs of Figure 2, where sub- 
jects played no more than once against any other player. As to expression, we sought to disaggregate legal expression into its components, so as to isolate the contribution of each. We identified three ways that legal expression might make a particular outcome focal: ostension, intentionality, and legitimacy. First, at its most minimal level, any relevant expression is ostensive, it "points to" and highlights a particular outcome by proclaiming it. Second, although nonhuman devices are capable of "pointing to" a particular outcome, law is also intentional - the product of conscious human decisions. Third, actors who pronounce legal rules, at least in a democratic society, tend to enjoy perceived legitimacy. Legitimacy may derive from being elected, appointed by others who are elected, or something else. Because each element of expression may plausibly contribute to the ability of law to create a focal point, we began with the first element—ostension-and then built up toward an approximation of legal expression.

At the same time, we avoided ever using legalistic expressions about "rules" or "penalties." We did this to avoid demand characteristics, where the subjects infer from the expression that the experimenter desires them to behave in a certain way. In addition, because law enjoys basic legitimacy among our subjects, we wanted to avoid terms that might invoke this legitimacy as a reason to comply. For example, we know that in a prisoners' dilemma game, experimenters can make behavior more cooperative by labeling it "The Community Game" or less cooperative by labeling it "The Wall Street Game" (Ross \& Ward 1996). Similarly, the presence in the laboratory of mundane physical objects like boardroom tables and briefcases decreases cooperativeness in social interactions (Kay et al. 2004). To avoid these effects, we use an abstract setting without terms making reference to law.

We thus contrasted a control condition, where the subjects played the game without receiving any expression other than the instructions, with three treatment conditions. In the first expressive condition, intended to model the minimalist effects of ostension, the experimenter spun a spinner before each round that would "point to" or highlight a particular equilibrium. In the second expressive condition, intended to model the added contribution of intentionality, a randomly selected subject identified as the "leader" recommended a particular outcome for each round. Legitimacy is itself a complex notion with many components. In the third expressive condition, intended to model the added contribution of only some minimal level of legitimacy, a "leader" selected by merit recommended a particular outcome for each round. Thus, each source of expression adds an additional 
Table 1: Experimental Design

\begin{tabular}{lll}
\hline Level & \multicolumn{1}{c}{ Condition } & Expressive Component \\
\hline 1 & Control & None \\
2 & Spinner & Ostension \\
3 & Random leader & Intentionality \\
4 & Merit-based leader & Minimal legitimacy \\
\hline
\end{tabular}

expressive property to the property introduced by the previous source of expression. The experimental design therefore consisted of one factor with four levels, as illustrated in Table 1.

\section{Procedure}

In each session, 10-14 subjects played about nine rounds of the HD game (the exact number depended on the number of participants in the session). Subjects were randomly assigned to expressive condition based on the session in which they participated. Subjects were promised a $\$ 10$ show-up fee and informed at the outset that they had the opportunity to earn or lose money, depending on their own decisions and the decisions of other participants in the session. Subjects were informed only that the session consisted of "a series of decision-making periods," but not the actual number. After the experimental instructions were distributed, the experimenter read them aloud to ensure that the participants shared common knowledge of the instructions. In each round, participants were randomly paired against an anonymous and different participant and were randomly assigned for that round to the role of "R" or "C." Players were paired against one another no more than once. Each counterpart was identified by a randomly assigned number, not by name, and the subjects did not know which identification number was associated with which player. In addition, the experimenter did not know the name of any subject.

In each round, Player $\mathrm{C}$ had to choose between C1 (Dove) or C2 (Hawk); Player R chose between R1 (Dove) or R2 (Hawk). Note that although we use the designations "Hawk" and "Dove" here for purposes of describing the experiment, we did not use these terms in any of the participants' experimental materials. Payoffs were the same as those of Figure 2, where each point represented \$1. After each round, each subject was informed of the decision of their "counterpart," as well as the resulting payoff. As the subjects were told, any money they earned or lost was added 
to or subtracted from their $\$ 10$ show-up fee. After the last round of the game, participants completed a questionnaire designed to assess their attitudes toward the game and to measure individual characteristics that might have influenced their choice of strategy. Final earnings were then computed by summing each participant's payoffs across all rounds. The experimenter then deposited the show-up fee plus or minus the final earnings into an envelope marked with the participant's identification number, and placed the envelopes on a table. On their way out, each participant approached the table one at a time, and picked up the envelope marked with their identification number.

Within each session, all subjects were assigned to the same condition. In the control condition, the participants played the HD game without expressive influence. In the spinner condition, we used a spinner each round to randomly highlight one equilibrium. The base of the spinner was divided into two equal parts, one of which read "R1/C2" and the other of which read "R2/C1." Recall that Strategy 1 signifies Dove and Strategy 2 signifies Hawk. Therefore, "R1/C2" signifies Row play Dove and Column play Hawk and "R2/C1" signifies the reverse. Before beginning the game, all participants in the spinner condition were instructed as follows:

Prior to each period, a spinner will be spun in view of everyone. You can see that the spinner will either point to "R1/C2" or "R2/C1." If you wish, you may consider the result of the spin in your decision, in whatever manner you choose. You are also entirely free to ignore it.

In the remaining two expressive conditions, two participants in each session were each selected to act as a "leader" for five rounds of the game by writing either "R1/C2" or "R2/C1" on a blackboard before each round. To control for "actor effects," we assigned two different participants to serve as the leader during each session, one for the first half of the session and one for the second half. We analyzed the data to examine whether there were significant differences in compliance based on leader identity; there were none. We controlled the message that the leader conveyed to ensure that the order of recommendations in the leader conditions exactly matched the random order determined by the spinner in the corresponding spinner condition, thus minimizing the error variance contributed by differences in order of messages. We kept the instructions to the leader confidential, so that the perceived source of the message was the leader (rather than the experimenter). This procedure helped minimize demand characteristics associated with the experimenter being the source of the message. To 
provide an incentive to convey the correct message, leaders were paid according to how many dyads in the session followed the message we supplied to them.

In the random leader condition, we explicitly used a random process to select the leader. Before beginning the game, the experimenter instructed the subjects as follows:

You have each been given a ticket when you first arrived at the experiment. In a moment, we will randomly select two ticket numbers from an envelope containing the numbered ticket stubs. Each of the two participants whose ticket numbers are selected will be designated the Leader for a portion of the session. Prior to each period, the Leader will have the opportunity to write a message on the blackboard. If you wish, you may consider the message in your decision, in whatever manner you choose. You are also entirely free to ignore it.

In the merit-based leader condition, we attempted to confer some minimal authority on the leader by informing participants that they would take a quiz, and that the two participants with the highest quiz scores would serve as leaders for the remainder of the session. The remainder of the instructions were identical to the above (i.e., they may consider the leader's message but are free to ignore it).

The quiz tested participants' knowledge on a topic they were likely to consider of some importance-the results of the statewide primary election that had recently occurred. Prior research suggested that subjects would perceive one's superior performance on a quiz as entitling him or her to a position of authority within the experiment. Hoffman et al. (1994) assigned subjects to a dictator game either randomly or according to a general knowledge quiz. Only 20 percent of randomly selected dictators allocated $\$ 0$ to their counterpart, but 40 percent of dictators selected by high quiz score allocated $\$ 0$ to their counterpart (see also Hoffman \& Spitzer 1985). Although these experiments necessarily establish only that the person selected by his or her superior performance will feel entitled to the position to which he or she is assigned, we believe it likely that other subjects will also share this view, and therefore that the leader selected by merit will be perceived to have some minimal moral authority lacking in the randomly selected leader.

Participants in the experiment were 103 undergraduate students who participated in exchange for a $\$ 10$ show-up fee. Of these, eight participants served as leaders, and so did not play the Hawk/Dove game. On average, subjects earned $\$ 7$ in addition to the show-up fee. The experiment lasted approximately one hour. 


\section{Hypotheses}

The three expressive components of law we tested in this experiment were ostension, intentionality, and minimal legitimacy. We hypothesized that each component would uniquely contribute to the influence of expression on participants' choice of strategy, as compared to the control. Specifically, we hypothesized: (1) that participants in the treatment conditions would be more likely to choose the recommended strategy than those in the control (i.e., that expression influences behavior); and (2) that compliance would increase as the message source reflected each additional expressive component (i.e., ostension $<$ intentionality $<$ minimal legitimacy).

\section{B. Results}

We designate the strategy indicated by the spinner or the leaders for each round as the focal strategy for that round. For convenience, we use the designation "focal strategy" even when describing the control condition, where there was no expression to make a strategy focal. Thus, in the control, "focal strategy" for round $n$ means the strategy recommended in the expressive conditions for round $n$. We then count an individual player's strategy choice as "compliance" if it corresponds to the focal strategy for that round. Recall that the focal message recommends one of two sets of strategies: either that Player R play Dove and Player C play Hawk, or that Player R play Hawk and Player $\mathrm{C}$ play Dove. Because we analyze the data at the level of the individual player, we code compliance as a dummy variable with values 1 or 0 , where 1 is the outcome when an individual player's chosen strategy matches the focal strategy recommended for that individual (or in the control condition, the strategy that would have been recommended had there been a message), and 0 where the player chooses the strategy not recommended.

The mean rate of compliance across expressive treatments is provided in Table 2. Note that the base rate for compliance in the absence of a message (in the control condition) is 0.51 , meaning that players choose the same strategy as the one that would have been recommended by the focal message (even in the absence of that message) about half the time (this is true necessarily because, whatever strategy a subject selects in a round of the control, there was a 50 percent probability it would be the strategy recommended for that round in the message conditions). Table 2 also shows that the rate of compliance appears to increase with the addition of each expressive component, as operationalized by each level of treatment. This trend appears to support the two hypotheses set forth earlier: first, that partici- 
Table 2: Summary of Data-Compliance Rates Across Treatments and Rounds

\begin{tabular}{lc}
\hline Variable & Mean Compliance Rate \\
\hline Control (none) & 0.51 \\
Spinner (ostension) & 0.65 \\
Random leader (intentionality) & 0.74 \\
Merit-based leader (minimal legitimacy) & 0.76 \\
Round 1 & 0.70 \\
Round 2 & 0.60 \\
Round 3 & 0.62 \\
Round 4 & 0.70 \\
Round 5 & 0.63 \\
Round 6 & 0.65 \\
Round 7 & 0.62 \\
Round 8 & 0.74 \\
Round 9 & 0.75 \\
Total & 0.67 \\
\hline
\end{tabular}

NoтE: "Compliance" is a dummy variable coded 1 if an individual player's choice matches the focal strategy and 0 otherwise. Mean compliance rate indicates the proportion of choices matching the focal strategy.

pants in the treatment conditions are more likely to choose the focal strategy than participants in the control condition (i.e., that expression influences behavior), and second, that compliance increases as the message source reflects each additional component.

\section{Hypothesis 1 (Control vs. Treatment)}

To test whether the addition of expression produced statistically reliable increases in compliance rates we estimated a series of probit regressions. In all of the probit models reported in this article, we estimated robust standard errors on the subject data to reflect that the data within subject are clustered rather than independent (Binder 1983). We also tested a model that included dummy variables for each of the rounds of play to examine whether compliance changed over time. Each of these independent variables is categorical, and the reported regression coefficients (DF/dx) denote the change in the probability that the dependent variable changes from 0 to 1 , that is, the change in probability of compliance. The reported $z$ statistic (analogous to the $t$ statistic in ordinary least squares regression) represents the ratio of the probit coefficient to its standard error.

First, we estimated a probit regression model to test the hypothesis that the players in the three treatment conditions (taken together) are more 
likely to choose the focal strategy than players in the control condition. Model 1 in Table 3 indicates that the treatment variable is statistically significant, which supports our hypothesis that participants in the treatment conditions were more likely to choose the focal strategy than participants in the control condition. Receiving a message of any kind (whether by spinner, random leader, or legitimate leader) increases the probability of choosing the focal strategy by 0.212 , compared to receiving no message.

We next examined whether the influence of focal point treatment is robust to whether Hawk or Dove is the recommended strategy. It could be

Table 3: Probit Analysis of Effect of Treatment, Message, and Rounds on Compliance

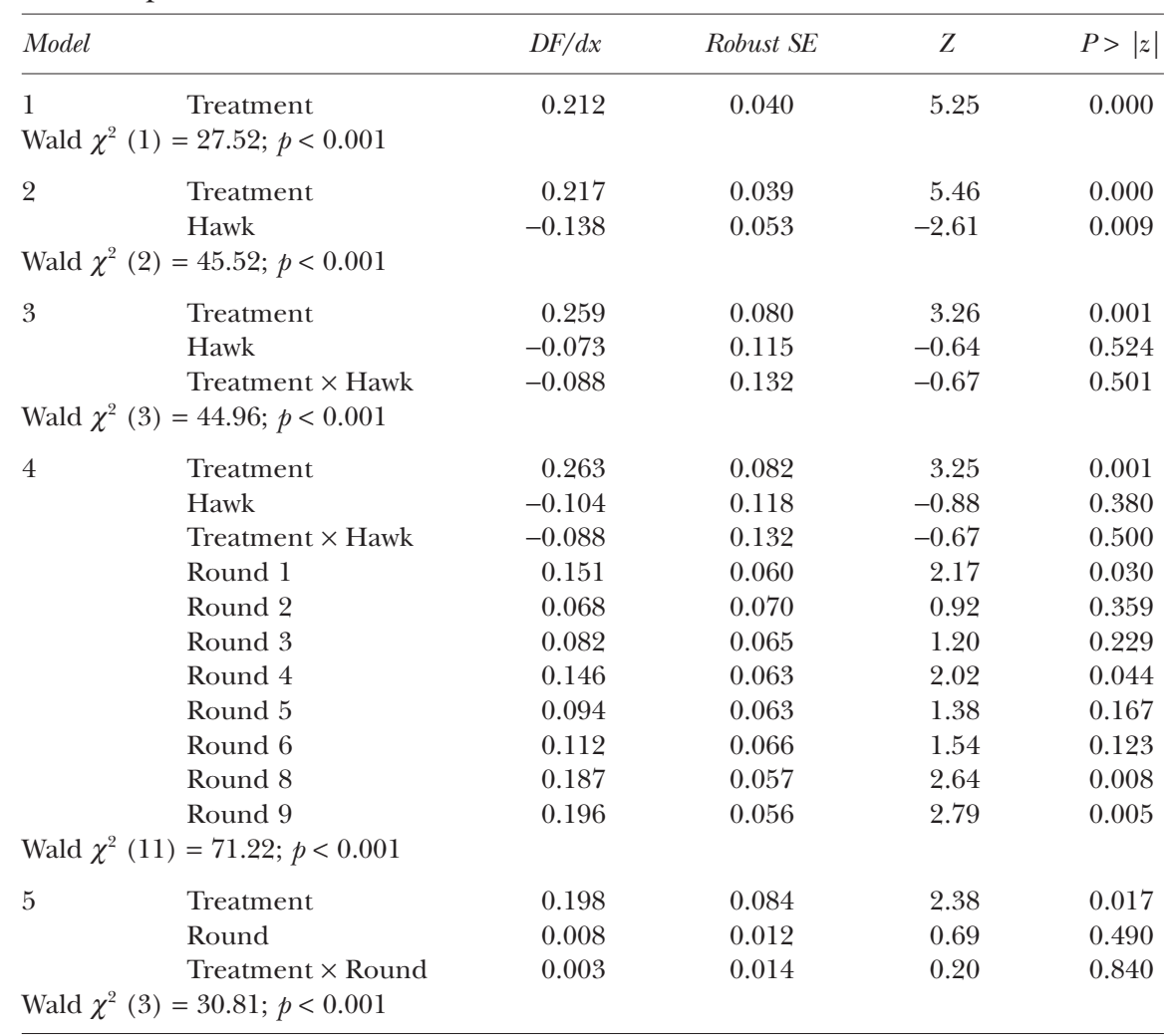

Note: $\mathrm{dF} / \mathrm{dx}$ is for discrete change of dummy variable from 0 to $1 ; z$ and $P>z$ tests whether the probit coefficient is equal to $0 . N=828$; standard error is adjusted for clustering around subject. 
the case that expression influences players' behavior more strongly when recommending that they play Dove or, conversely, when recommending that they play Hawk. We note initially that in the absence of any message (control condition), players chose Hawk 41 percent of the time. This tendency to choose Hawk roughly 40 percent of the time is fairly consistent across the different treatment conditions, as shown in Table 4. (There are no statistically significant differences in proportion of individual Hawk choice across treatment, $F(3)=0.599 ; p=0.62$.) Although there is some variation in Hawk playing across rounds, there are no discernable patterns over time. Table 4 also depicts, at the dyad level, the rate of Hawk-Hawk outcomes. This rate is 0.16 in the control condition, and appears slightly lower in the treatment conditions, although an analysis of variance reveals that these overall differences do not reach conventional levels of statistical significance $(F(3)=$ $1.74 ; p=0.16)$. Given this base rate of Hawk playing, we now return to the question of whether magnitude of the expressive effect of the message depends on whether Hawk or Dove is the recommended strategy.

To accomplish this, we estimated a probit model that included both the treatment variable and a dummy variable called "Hawk" that is assigned the value of 1 when the focal strategy recommended that the player choose Hawk and 0 otherwise. Model 2 in Table 3 indicates that there was a significant difference in compliance when Hawk was the focal strategy, so that players were less inclined to comply when Hawk was recommended compared to when Dove was recommended, reflecting perhaps the overall greater tendency to choose Dove as discussed earlier. At the same time, the treatment variable remains statistically significant even when Hawk was recommended. For each of the focal strategies (Hawk and Dove), the message increased compliance compared to the control condition. These two main effects of treatment and Hawk are illustrated graphically in Figure 3, which shows that players complied more when Dove was recommended compared to Hawk, and at the same time players complied more when a focal strategy was provided compared to when there was none.

Model 3 in Table 3 examines the interaction of treatment (whether or not there was a message) and Hawk (whether the message made Hawk focal or Dove focal). There was no statistically significant treatment $\times$ Hawk interaction, suggesting that the magnitude of influence of the message in the treatment conditions did not depend on whether Hawk or Dove was the focal strategy. Instead, the message was equally as influential when Hawk was the focal strategy as when Dove was the focal strategy. In sum, subjects selected Hawk less often in the control than they selected Dove, and by about 
112 Testing the Focal Point Theory of Legal Compliance

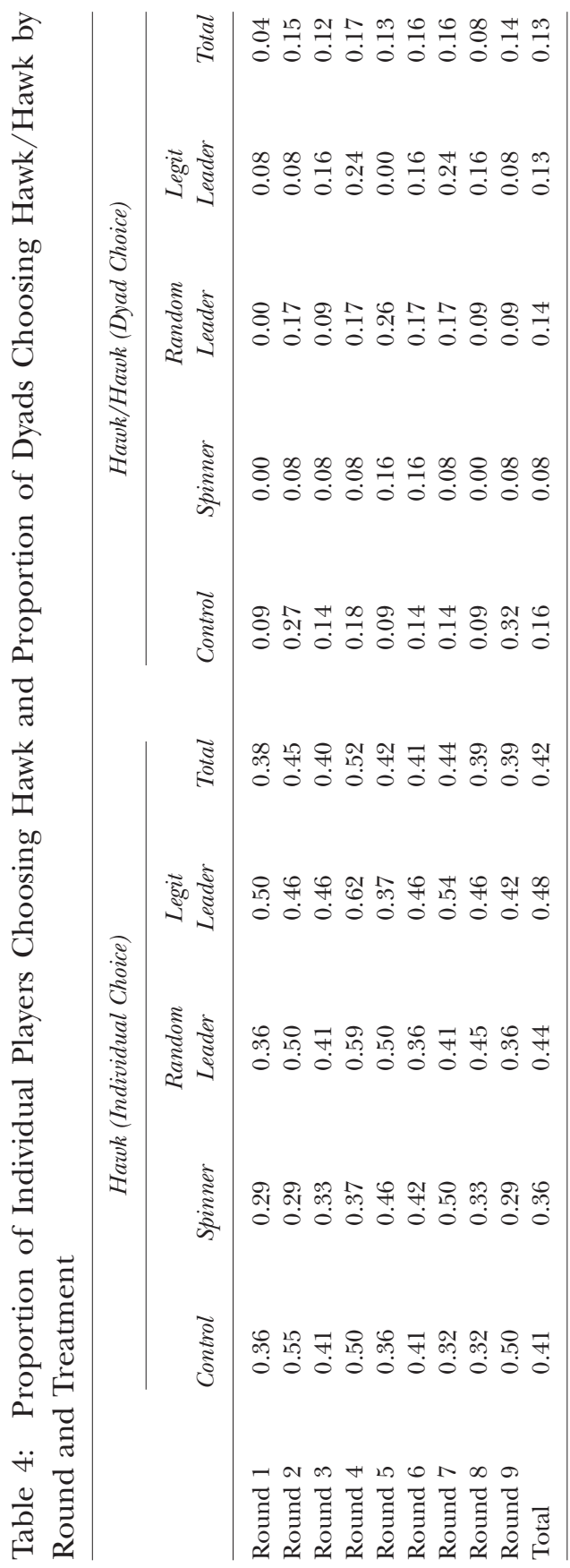


Figure 3: Compliance as a function of recommendation.

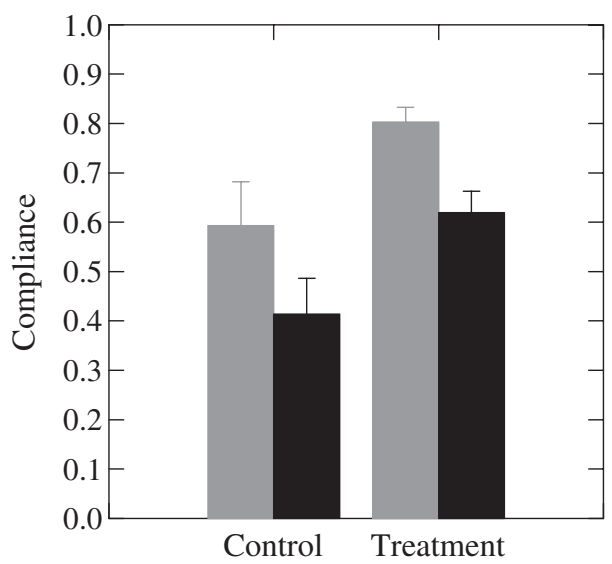

Recommended Strategy

Dove

- Hawk

NotE: Compliance indicates the proportion of choices matching the recommended strategy.

the same amount subjects selected Hawk less often in the treatment conditions than they selected Dove, but they were significantly more likely to select the recommended strategy in the treatment conditions-whether Hawk or Dove-than in the control.

The addition of dummy variables for round in Model 4 (Table 3) also allows us to demonstrate that the treatment effect remains robust while controlling for any possible effects attributable to round of play, a topic to which we return later. We also ensured that there were no different trends in compliance over time across treatment by testing a model that examines the interaction of round and treatment. Model 5 (Table 3) tests for this interaction and shows that there are no linear trends over round that depend on treatment group.

Next, we estimated a model that included dummy variables for each of the treatment conditions (spinner, random leader, merit-based leader), as well as dummy variables for each of the periods of play. This model allows us to separately compare each of the components of expressive influence to the control condition. The addition of the dummy variables for round again allows us to examine whether such effects remain robust while controlling for any possible effects attributable to round of play. Model 1 in Table 5 indicates statistically significant effects for each of the three components of expression that were operationalized in the treatment conditions. Compared 
Table 5: Probit Analysis of Effect of Individual Focal Message Treatments and Rounds on Compliance

\begin{tabular}{|c|c|c|c|c|c|}
\hline Model & & $d F / d x$ & Robust SE & $Z$ & $P>|z|$ \\
\hline \multirow[t]{3}{*}{1} & Ostension (spinner) & $0.131^{\mathrm{a}}$ & 0.040 & 3.08 & 0.002 \\
\hline & Intentionality (random leader) & $0.209^{\mathrm{a}, \mathrm{b}}$ & 0.045 & 3.89 & 0.000 \\
\hline & $\begin{array}{l}\text { Minimal legitimacy (merit- } \\
\text { based leader) }\end{array}$ & $0.226^{\mathrm{b}}$ & 0.041 & 4.72 & 0.000 \\
\hline \multicolumn{6}{|c|}{ Wald $\chi^{2}(3)=30.04 ; p<0.001$} \\
\hline \multirow[t]{11}{*}{2} & Ostension (spinner) & 0.132 & 0.040 & 3.08 & 0.002 \\
\hline & Intentionality (random leader) & 0.211 & 0.046 & 3.86 & 0.000 \\
\hline & $\begin{array}{l}\text { Minimal legitimacy (merit- } \\
\text { based leader) }\end{array}$ & 0.227 & 0.041 & 4.70 & 0.000 \\
\hline & Round 1 & -0.060 & 0.073 & -0.84 & 0.400 \\
\hline & Round 2 & -0.168 & 0.069 & -2.54 & 0.011 \\
\hline & Round 3 & -0.145 & 0.081 & -1.84 & 0.066 \\
\hline & Round 4 & -0.062 & 0.071 & -0.90 & 0.369 \\
\hline & Round 5 & -0.134 & 0.068 & -2.01 & 0.044 \\
\hline & Round 6 & -0.109 & 0.074 & -1.53 & 0.127 \\
\hline & Round 7 & -0.144 & 0.084 & -1.76 & 0.079 \\
\hline & Round 8 & -0.012 & 0.075 & -0.16 & 0.872 \\
\hline \multicolumn{6}{|c|}{ Wald $\chi^{2}(11)=53.27 ; p<0.001$} \\
\hline \multirow[t]{2}{*}{3} & Ostension (spinner) & $0.131^{\mathrm{a}}$ & 0.040 & 3.08 & 0.002 \\
\hline & Leadership (random \& merit leaders) & $0.237^{\mathrm{b}}$ & 0.040 & 5.36 & 0.001 \\
\hline Wald $\chi$ & $(2)=29.44 ; p<0.001$ & & & & \\
\hline
\end{tabular}

Note: $\mathrm{dF} / \mathrm{dx}$ is for discrete change of dummy variable from 0 to $1 ; z$ and $P>z$ tests whether the probit coefficient is equal to $0 . N=828$; standard error is adjusted for clustering around subject. Within each model, chi-square tests for equality of probit coefficients are designated by superscript letters next to the $\mathrm{DF} / \mathrm{dx}$ coefficient; two coefficients marked with different letters indicate significant differences at $p<0.05$.

to the control condition, the probability of choosing the focal strategy increases by 0.13 when that strategy is made focal through ostension alone (spinner); the probability increases by 0.21 when that strategy is made focal through ostension and intentionality (random leader); and the probability increases by 0.23 when that strategy is made focal through ostension, intentionality, and minimal legitimacy (merit-based leader).

Note that the $\mathrm{dF} / \mathrm{dx}$ marginal effects illustrated in Table 5 are very close to differences suggested by the sample means in Table 2. For example, Table 2 suggests a 0.14 increase in probability of playing the focal strategy in the spinner condition compared to the control condition, a marginal effect very close to that indicated by the $0.131 \mathrm{dF} / \mathrm{dx}$ coefficient for spinner in Table 5. The marginal effects of random leader and merit-based leader 
shown in Table 5 are also close to the differences in the respective means depicted in Table 2. These similarities suggest that even after controlling for the effects of round (recall that a few of the coefficients were statistically significant), the treatment coefficients (for spinner, random leader, and merit-based leader) remain essentially unchanged.

Model 2 in Table 5 includes dummy variables for individual rounds of play. Recall that players played about nine rounds of the game, each against a different opponent. The probit coefficients for a few of the individual round dummies are statistically significant. In this model, Round 9 is the omitted variable, so that in Rounds 2 and 5 the probability of compliance is less than in Round 9. However, there does not seem to be any discernible trend of increasing or decreasing probability of compliance across rounds. Most important, the treatment dummies are still significant even with the round dummies included in the model, indicating that the effect of treatment is robust to any influence of round.

\section{Hypothesis 2 (Ostension vs. Intentionality vs. Minimal Legitimacy)}

We next tested whether compliance increases as the message source reflects each additional expressive component. The results discussed in the last section demonstrated that the presence of any expression results in higher compliance, compared to no focal point (see Table 3, Model 1). Given that we have shown that the constructed focal point has an effect, we now explore differences attributable to type of message source, using a set of planned contrasts. To do this, we first examine the effect of leadership per se against the effect of ostension, to show that a message delivered by a human influences compliance more than a message that simply points (as with the spinner). We created a dummy variable for leadership, which combines the intentionality (random leader) and the minimal legitimacy (legitimate leader) variables. Model 3 confirms that the probability of choosing the focal strategy is higher when that strategy is made focal (either via ostension or via leadership) than when the strategy is not made focal (control). More importantly, tests of equality of the probit coefficients in Model 3, Table 5 indicate that there was a statistically significant difference between spinner and leadership (random and merit-based leader taken together). Finally, we tested for differences between the two leadership conditions and found that the probit coefficients of random leader and legitimate leader in Model 1, Table 5 are equal. Thus, we detected no difference between the two leadership conditions in the probability of choosing the focal strategy. Nonethe- 
less, though the ment-based leader alone differed from the spinner, the random leader did not (Model 1, Table 5).

After the last round of the game we administered a questionnaire designed to measure attitudes toward the game and individual personality and demographic characteristics that might have influenced their choices. None of the individual characteristics we measured predicted choices in the game, so we omit these results for purposes of brevity. However, attitudes about their counterparts' strategy choices did matter. Participants indicated on a seven-point scale their attitudes about the fairness of their opponents' choices $(1=$ extremely unfair; $7=$ extremely fair $)$. We found that whenever the counterpart chose the focal strategy, this was perceived by the target player as more fair $(M=5.30)$ than when the counterpart chose the nonfocal strategy $(M=4.54) ;(t(72)=3.98 ; p<0.001)$.

We also found that when the counterpart disregarded the focal strategy, the magnitude of perceived unfairness depended on whether Hawk or Dove was the focal strategy. To analyze this issue, we first computed a difference score by subtracting fairness of playing Hawk when not recommended ( 1 = extremely unfair; $7=$ extremely fair) from fairness of playing Hawk when recommended $(M=1.15)$. We computed a similar difference score for fairness of playing Dove $(M=0.36)$. We then used a paired $t$ test to analyze whether there was a difference between these two difference scores. The difference was significant: $t(72)=-4.07 ; p<0.001$. Thus, when the focal strategy for the counterpart was Dove but the counterpart ignored the message and played Hawk, this was perceived as considerably less fair than when the reverse occurred (focal strategy was Hawk and counterpart played Dove). It appears that playing Dove is perceived as basically fair regardless of the message, but playing Hawk is perceived as fair only when authorized by the message.

\section{Discussion}

Most theorists of legal compliance would concede that third-party expression will by itself influence behavior in a pure coordination game, such as the choice between driving on the left or right side of the road. Previous experiments support this claim. The results here, however, suggest something more surprising, that third-party expression can by itself influence the behavior of individuals outside of a pure coordination game, in a situation involving significant conflict. The results are robust across the recommendation (Hawk or Dove) and across round (1-9). That something as arbitrary 
as a spinner made subjects more likely to choose a particular strategy, compared to the control, suggests that expression can influence behavior ostensively. Merely pointing to an equilibrium appears to increase the salience of that choice, which increases the likelihood that players will choose the strategies producing that equilibrium. That players are likely to choose a strategy that the spinner plainly selects at random suggests that expression influences behavior even when it lacks legitimacy or intentionality. Legal expression always "points to" an outcome. Law influences behavior in many ways, but we infer from this result that, at the most basic level, law also influences behavior ostensively. That is, in coordination situations, law works in part by merely pointing to the prescribed outcome.

There remains a question of the precise mechanism that produces the behavioral influence. Salience might work unreflectively, merely because it causes a certain strategy to be "on the mind" of each subject, or reflectively, because it also causes each subject to expect his or her counterpart to play the salient strategy. These possibilities correspond to what Mehta et al. (1994) respectively term as "primary" and "secondary" salience. The wellknown Anchoring and Adjustment experiment by Tversky and Kahneman (1982) may be interpreted as showing that a random device can work via primary salience. They used a "wheel of fortune" displaying numbers to influence the estimates subjects made in answering quantitative questions. The random number displayed immediately before subjects gave an answer influenced the answer even though it was logically irrelevant. Our experiment does not involve an adjustment process by which the subjects understand that the salient choice is incorrect and insufficiently adjust away from the incorrect choice. Nonetheless, because expectations about other's behavior were irrelevant to answering the questions posed, the Tversky and Kahneman study suggests that salience can work without affecting such expectations. By contrast, Mehta et al. (1994) find that when subjects have an incentive to coordinate, they reason about what others will find salient. Thus, in our experiment, it seems likely that the expression works via secondary salience, by influencing expectations of what other subjects will do.

When the source of expression was a leader, there was a trend toward an additional influence of expression on players' choices, over and above the ostensive influence of the spinner. There was no significant difference between the spinner and the random leader nor between the random and merit-based leader, but there is a significant difference between the spinner and the merit-based leader. When we collapsed these two leader conditions, we found significantly greater compliance when the leader delivered the 
message, as compared to the spinner. The trend suggests that the leader itself might provide a stronger expressive source than a purely mechanical device, and that a stronger, more comprehensive manipulation of legitimacy than our political quiz might increase compliance considerably, perhaps significantly more than a random leader. As matters stand, even the process of selecting the leader by a quiz on recent political events was sufficient to endow the leader with some expressive power greater than the spinner. We conjecture that the effect arises from a minimal form of perceived legitimacy, based either on the perception that the merit-based selection process was more "fair" than random selection or that the leader was perceived as more competent or credible.

Finally, it is intriguing that subjects so quickly came to equate "fairness" with playing the recommended strategy, even when the recommendation came arbitrarily from a spinner and despite the abstract context of the interaction. We can speculate why. As noted above, all the subjects improve their ex ante (but not ex post) payoffs if they all coordinate their strategies with a random event they both observe, like the spinner, thereby avoiding the possibility of a Hawk/Hawk outcome. We think it possible that many subjects recognized this fact and perceived the method for maximizing their joint returns as "fair." As a result, subjects may have perceived as "unfair" the noncompliance that produces or risks the Hawk/Hawk outcome, that is, where one plays Hawk contrary to the third-party message. If so, then the experiment suggests an insight into one source of law's "legitimacy" (even though our primary focus is a compliance mechanism other than legitimacy). In situations involving coordination, legitimacy may arise, not because law embodies a community's moral norms, nor because a democratic process produces the law, but because law provides an arbitrary way to coordinate strategies. It is not (or not merely) that the law reminds or persuades people of their moral obligations, but that people feel obligated in coordination situations to do whatever is, by virtue of its salience, expected of them. ${ }^{3}$

\footnotetext{
${ }^{3}$ We can also speculate about the related finding that it is more "unfair" to play Hawk in response to a Dove recommendation than to play Dove in response to a Hawk recommendation. In the latter case, one apparently intends to produce the outcome Dove/Dove, which is equally efficient as the two equilibria and produces equal payoffs. As in ultimatum games, many apparently regard the equal split as fair (Falk et al. 2003; Messick \& Sentis 1985).
} 


\section{Conclusion}

In this article, we argue that coordination situations involving conflict frequently occur in the real world, and that law can potentially influence behavior in these situations by constructing a focal point. As other public rituals generate common knowledge (Chwe 2001), we have plausibly assumed that law is frequently capable of drawing attention to the equilibrium outcome it prescribes. By publicly announcing a state of affairs (e.g., "No Smoking Here" or "The disputed property belongs to $A$ ") law can make one of the multiple equilibria salient. We tested whether third-party expression can, by making an outcome salient, influence the behavior of the players in the game. In the Hawk/Dove game we used, each player preferred a different equilibrium from his or her counterpart. Yet despite this conflict, a third party's "mere" cheap talk significantly influenced the players' behavior. Thus, if coordination problems of the kind modeled by the Hawk/Dove game are common, and if law tends to draw attention to the outcome it prescribes, then law works, in part, by creating a focal point. Sanctions and legitimacy do not exhaust the mechanisms by which law influences behavior.

More specifically, we tested how certain features of cheap talk contribute to its ability to influence behavior. Most of the expressive power we discovered exists in the most minimal expressive condition we tested: when an explicitly random mechanical device "points to" a symbol of one or another equilibrium. Adding the component of intentionality by having a randomly selected leader deliver the message did not reliably enhance the influence of the message. But adding a minimal form of legitimacy, by using a merit-based process for selecting the leader who delivers the message, did reliably enhance its influence. Finally, we find that subjects are quick to equate "fairness" with an individual's playing Dove when the message so indicates.

The experiment we report represents only an initial effort to test the focal effects of law. Although the experimental setting is highly stylized, the method is highly appropriate for a first test of the law's focal point influence because it is so difficult in the real world to separate that influence from the influence of sanctions and legitimacy. Moreover, the use of experimental methods allows us to manipulate precisely the source of influence on behavior (even isolating individual components of expressive influences), and therefore to make strong causal inferences about the influence of expression on behavior. Nonetheless, our experimental results leave open substantial questions for future research. We note that the participants in our 
experiment were undergraduate students, and subsequent experiments should investigate whether the decisions of community members playing the game differ from those of the participants in this experiment. Additionally, the context of the experiment was sparse, with the two alternatives given austere labels (Strategy 1 and Strategy 2), and the effect of legal pronouncements modeled with an announcement made by means of a spinner or a participant in the room. Indeed, we intentionally designed the laboratory "set" to be as sparse as possible in an effort to avoid subtle contextual cues demonstrated to have surprising influence in other settings. On the one hand, our use of an abstract experimental setting scrupulously avoids unanticipated effects of contextual cues; on the other hand, our sparse laboratory set is not designed to model contextual effects present outside the laboratory, such as those that arise from interpersonal interaction, prior experience, and default rules, to name just a few. The testing of these possibilities must be left to future experiments.

Even within the current structure of the experiment, there are many variations left to explore. One might test the robustness of the basic findings in divergent strategic settings-different games, payoffs, information sets, and so forth. One could usefully test whether ostension works merely through primary (unreflective) salience or because it makes players form new expectations about what the other player will do. Additionally, it would be productive to introduce additional components of legal expression. In particular, one might seek to test whether the ostensive influence we identify remains powerful when compared to leaders endowed with a stronger form of legitimacy. Nonetheless, we have made a start here in showing how one may use experiments to explore the sources of the law's expressive power.

\section{REFERENCES}

Ahdieh, R. B. (2004) "Law's Signal: A Cueing Theory of Law in Market Transition," 77 Southern California Law Rev. 215.

Bednar, J., \& S. Page (2003) Can Game(s) Theory Explain Culture? Working paper. Available at <http://www-personal.umich.edu/ jbednar/WIP/culoct14.pdf $>$.

Binder, D. A. (1983) "On the Variances of Asymptotically Normal Estimators from Complex Surveys," 51 International Statistical Rev. 279.

Bohnet, I., \& R. Cooter (2001) Expressive Law: Framing of Equilibrium Selection? Unpublished manuscript. 
Brandts, J., \& C. A. Holt (1992) "An Experimental Test of Equilibrium Dominance in Signaling Games," 82 American Economic Rev. 1350.

Brandts, J., \& W. B. MacLeod (1995) "Equilibrium Selection in Experimental Games with Recommended Play," 11 Games E Economic Behavior 36.

Brown, J. G., \& I. Ayres (1994) "Economic Rationales for Mediation," 80 Virginia Law Rev. 323.

Chaudhuri A., \& S. Graziano (2003) Evolution of Conventions in an Experimental Public Goods Game with Private and Public Knowledge of Advice. Unpublished manuscript.

Chong, D. (2000) Rational Lives: Norms and Values in Politics and Society. Chicago, IL: Univ. of Chicago Press.

Chwe, M. S. (2001) Rational Ritual. Princeton, NJ: Princeton Univ. Press.

Cooter, R. (1998) "Expressive Law and Economics," 27 J. of Legal Studies 585.

Crawford, V. (1998) "A Survey of Experiments on Communication via Cheap Talk," $78 \mathrm{~J}$. of Economic Theory 286.

Croson, R., \& M. Marks (2001) "The Effect of Recommended Contributions in the Voluntary Provision of Public Goods," 39 Economic Inquiry 238.

Dharmapala, D., \& R. McAdams (2003) "The Condorcet Jury Theorem and the Expressive Function of Law: A Theory of Informative Law," 5 American Law $\mathcal{E}$ Economics Rev. 1.

Duffy, J., \& E. Fisher (forthcoming) "Sunspots in the Laboratory," American Economic Rev.

Falk, A., E. Fehr, \& U. Fischbacher (2003) “On the Nature of Fair Behavior," 41(1) Economic Inquiry 20.

Farrell, J., \& M. Rabin (1996) "Cheap Talk," 10 J. of Economic Perspectives 103.

Fehr E., U. Fischbacher, \& S. Gachter (2002) "Strong Reciprocity, Human Cooperation, and the Enforcement of Social Norms," 13 Human Nature 1.

Fudenburg, D., \& J. Tirole (1991) Game Theory. Cambridge, MA: MIT Press.

Garrett, G., \& B. R. Weingast (1993) "Ideas, Interests, and Institutions: Constructing the European Community's Internal Market," in J. Goldstein \& R. O. Keohane, eds., Ideas and Foreign Policy: Beliefs, Institutions, and Political Change. Ithan, NY: Cornell Univ. Press.

Ginsburg, T., \& R. McAdams (2004) "Adjudicating in Anarchy: An Expressive Theory of International Dispute Resolution," 45 William E Mary Law Rev. 1229.

Hardin, R. (1989) "Why a Constitution?” in B. Grofman \& D. Wittman, eds., The Federalist Papers and the New Institutionalism. New York: Agathon Press.

Harel, A., \& A. Jacob (2002) "An Economic Rationale for the Legal Treatment of Omissions in Tort Law: The Principle of Salience," 3 Theoretical Inquiries in Law 413.

Hay, J. R., \& A. Shleifer (1998) "Private Enforcement of Public Laws: A Theory of Legal Reform," 88 American Economic Rev. 398.

Henrich, J., R. Boyd, S. Bowles, C. Camerer, E. Fehr, H. Gintis, \& R. McElreath (2001) "In Search of Homo Economicus: Behavioral Experiments in 15 Small-Scale Societies," 91 American Economic Rev. 73. 
Hermalin, B. (2001) "Economics and Corporate Culture," in C. Cooper, S. Cartwright, \& P. Earley, eds., The International Handbook of Organizational Culture and Climate, ch. 10. New York: John Wiley \& Sons.

Hoffman, E., A. McCabe, K. Shachat, \& V. Smith (1994) "Preferences, Property Rights and Anonymity in Bargaining Games," 7 Games $\mathcal{E}$ Economic Behavior 346.

Hoffman, E., \& M. Spitzer (1985) "Entitlements, Rights and Fairness: An Experimental Examination of Subjects' Concepts of Distributive Justice," $14 \mathrm{~J}$. of Legal Studies 259.

Kahan, D. M. (2000) "Gentle Nudges vs. Hard Shoves: Solving the Sticky Norms Problem," 67 Univ. of Chicago Law Rev. 607.

Kay, A. C., J. A. Bargh, J. S. Wheeler, \& L. Ross (2004) "Material Priming: The Influence of Mundane Physical Objects on Situational Construal and Competitive Behavioral Choice," 95 Organizational Behavior \& $\mathcal{E}$ Human Decision Processes 83.

Kreps, D. M. (1990) "Corporate Culture and Economic Theory," in J. E. Alt \& K. A. Shepsle, eds., Perspectives on Positive Political Economy. Cambridge: Cambridge Univ. Press.

McAdams, R. (2000a) “A Focal Point Theory of Expressive Law," 86 Virginia Law Rev. 1649.

McAdams, R. (2000b) “An Attitudinal Theory of Expressive Law," 79 Oregon Law Rev. 339.

McAdams, R. (forthcoming) "The Expressive Power of Adjudication," Univ. Illinois Law Rev.

McCabe, K. A., S. J. Rassenti, \& V. L. Smith (1998) "Reciprocity, Trust, and Payoff Privacy in Extensive Form Bargaining," 24 Games Eै Economic Behavior 10.

Mehta, J., C. Starmer, \& R. Sugden (1994) "The Nature of Salience: An Experimental Investigation of Pure Coordination Games," 84 American Economic Rev. 658.

Messick, D. M., \& K. P. Sentis (1985) "Estimating Social and Nonsocial Utility Functions from Ordinal Data," 15 European J. of Social Psychology 389.

Posner, E. A. (2000) Law and Social Norms. Cambridge, MA: Harvard Univ. Press.

Ross, L., \& A. Ward (1996) "Naïve Realism in Everyday Life: Implications for Social Conflict and Misunderstanding," in T. Brown, E. Reed, \& E. Turiel, eds., Values and Knowledge, pp. 103-35. Hillsdale, NJ: Erlbaum.

Schelling, T. C. (1960) The Strategy of Conflict. Cambridge, MA: Harvard Univ. Press.

Schotter A., \& B. Sopher (2003) "Social Learning and Coordination Conventions in Intergenerational Games: An Experimental Study," $111 \mathrm{~J}$. of Political Economy 498.

Strauss, D. (1996) “Common Law Constitutional Interpretation," 144 Univ. of Chicago Law Rev. 877.

Sugden, R. (1986) The Economics of Rights, Cooperation and Welfare. Oxford, UK: Basil Blackwell.

Tversky, A., \& D. Kahneman (1982) "Judgment Under Uncertainty: Heuristics and Biases," in D. Kahneman, P. Slovic, \& A. Tversky, eds., Judgment Under Uncertainty: Heuristics and Biases, pp. 3-22. New York: Cambridge Univ. Press. 
Tyran, J.-R., \& L. P. Feld (2002) Why People Obey the Law: Experimental Evidence from the Provisions of Public Goods. Unpublished manuscript.

Valley, K. L., L. Thompson, R. Gibbons, \& M. Bazerman (2002) "How Communication Improves Efficiency in Bargaining Games," 38 Games $\mathcal{E}$ Economic Behavior 127.

Van Huyck, J. B., A. B. Gillette, \& R. C. Battalio (1992) "Credible Assignments in Coordination Games," 4 Games E Economic Behavior 606.

Wilson, R. K., \& C. M. Rhodes (1997) "Leadership and Credibility in N-Person Coordination Games," 41 J. of Conflict Resolution 767. 